\title{
A INVEJA E MODALIDADES DE INTERAÇÃO
}

Dionei Mathias (UFSM)

Resumo: Em muitas obras de Elfriede Jelinek, a inveja tem um papel importante no que concerne às interações das personagens. Isso vale especialmente para o romance $A$ pianista, publicado em alemão em 1983, em que mãe e filha se veem confrontadas com essa emoção. A inveja, como resultado de uma determinada interpretação da realidade, produz uma série de comportamentos decorrentes da convicção de que o sujeito é vítima de uma injustiça, o que em sua visão legitima reações eticamente questionáveis. No romance a ser analisado, há três configurações de interação que explicitam a dinâmica da inveja e revelam a maleabilidade da argumentação com o objetivo de legitimar comportamentos: o relacionamento entre mãe e filha, entre professora e alunos, por fim, a dinâmica entre gerações.

Palavras-Chave: Elfriede Jelinek; Die Klavierspielerin; A pianista; Inveja.

Abstract: In many texts written by Elfriede Jelinek, envy plays a central role as far as interactions shown by characters are concerned. This applies specially to the novel The Piano Teacher, published in German in 1983, in which mother and daughter are confronted with this emotion. Envy, as a result of a specific reality interpretation, produces a behavior associated with the belief of the subject suffering an injustice, which in his/her view serves as legitimization of ethically questionable reactions. In the novel in focus, there are three interactional configurations which make the dynamics of envy very explicit and reveal the malleability of argumentation whenever certain kinds of behavior are in need of legitimization: the relationship between mother and daughter, between teacher and students, at last, between different generations.

Keywords: Elfriede Jelinek; Die Klavierspielerin; The Piano Player; Envy.

\section{INTRODUÇÃO}

Inveja significa um desgosto ou pesar pela felicidade alheia, acompanhados por uma premência incontrolável de possuir 
o objeto da felicidade da pessoa em vista. Etimologicamente oriunda do vocábulo latim "invidere", uma combinação do prefixo "in" e do verbo "videre", a palavra inveja conota, com teor semântico inerente ao prefixo, um olhar atravessado, perfurador, que almeja aniquilar a pessoa observada. Essa emoção, considerada negativa, contém uma série de matizes emotivos, que em sua totalidade formam a base para a percepção desse conceito como algo quase tangível, pela malevolência que o impele. Dentre as muitas nuanças que a caracterizam, encontram-se as sensações de hostilidade, inferioridade e impotência (SCHOECK, 1987).

O olhar de esguelha sufoca a possibilidade de uma interação que transcenda a percepção do objeto cobiçado. Confrangidos pela incapacidade de possuir o tesouro alheio, as protagonistas do romance $A$ pianista de Elfriede Jelinek (1983 em alemão, 2011 na tradução brasileira) se retorcem interiormente, sem conseguir transpor a barreira que as impossibilita de criar laços interativos duradouros e capazes de libertá-las das garras da solidão. A visão da ambição coibida representa o início e, inexoravelmente, também o fim de todas suas interações. A despeito de sua necessidade de proteção e de proximidade humana, não reconhecem, em instante algum, a lógica cruel de suas emoções, 
permanecendo escravas de uma inveja que inibe qualquer outra visão de mundo. Scholz (2010) fala de uma poética visual, Wilke (1993) e Burger (1990) discutem a encenação do olhar malvado sobre o outro. Neste artigo, pretende-se analisar as modalidades de interação na configuração de personagens, atentando especialmente ao modo como a inveja é dita e a seu impacto na visão de mundo da mãe e da professora, Erika Kohut.

\section{NEGOCIAÇÕES ENTRE MÃE E FILHA}

O olhar paralisante se espraia já na primeira e mais importante interação social da professora de piano, Erika Kohut, a saber, em casa, na relação entre mãe e filha. A matriarca, possessiva e intransigente, não suporta nem sequer a mais ligeira insinuação de um pensamento que pudesse indicar que a filha mantém uma existência que escape a suas determinações ou ambições. Para assegurar sua onipresença na vida da filha, controla-a com a minuciosidade de uma agente secreta, empregando para isso, se a pertinácia da filha o exige, as artimanhas da chantagem emocional, obliterando sistematicamente a idade adulta da filha de sua memória funcional.

A filha, afeita à zona de conforto à qual obviamente não quer renunciar, tolera a arbitrariedade materna e renuncia 
voluntariamente a sua maioridade. Isso, no entanto, não significa que ela não tente articular ou, ao menos, encenar o desejo de certa autonomia existencial com a qual pudesse definir independentemente os caminhos que tenciona perseguir:

Ela luta tenazmente contra os laços
maternos e tenta não ser chamada por
telefone, mas a mãe facilmente consegue
transpor essas barreiras, pois é ela quem
define os mandamentos, sozinha. É
também ela quem define quem pode ou
não procurar pela filha. O resultado disso
é que há cada vez menos pessoas que
desejam vê-la ou falar com ela. (JELINEK,
2011, p.12)

Prescrevendo as leis que regem a vida da filha e determinando o diâmetro das relações sociais que ela possa vir a ter, a mãe define as coordenadas nas quais Erika Kohut pode se movimentar.

A inveja materna tem diversos motivos, todos eles determinando o modo como a mãe interage com a filha. No centro, pode-se identificar seu receio de testemunhar que a filha alcance uma autonomia que a torne supérflua. Tendo em vista que a mãe não possui autonomia suficiente para enveredar por caminhos existenciais independentes, seu olhar de inveja recai sobre Erika, de quem desconfia continuamente, a despeito de sua obediência quase infantil. Ao vislumbrar a 
possibilidade da filha de construir uma carreira, tecer laços de amizade, encontrar um companheiro ou simplesmente desejar ter seu próprio espaço, a mãe reage com estratégias que sufocam e exterminam definitivamente esses ímpetos.

A motivação subjacente não pode ser reduzida ao desejo de proteção, com o qual a mãe tenta narrar suas ações e legitimálas para si e sua filha. Embora ela busque repetidamente se autocaracterizar como inquieta e apreensiva com o futuro da musicista, o que, de fato, cunha seu comportamento é o medo de experimentar a desagradável sensação de enxergar a superioridade da filha quanto à realização pessoal. Ela não se apercebe de seus sentimentos mesquinhos, muito pelo contrário, ela crê estar fazendo o melhor possível para proteger Erika dos infortúnios que distinguem sua própria existência. A necessidade implícita de parafrasear a inveja com uma ficção em consonância com os preceitos éticos vigentes está vinculada, por um lado, à necessidade da mãe de legitimar seu comportamento de uma maneira plausível aos olhos da filha; por outro lado, a mãe tem necessidade de uma história que não mine seu conceito de dignidade pessoal e torne sua autoimagem inaceitável.

Apesar de ter sua liberdade quase que irrestritamente limitada, Erika se submete aos caprichos da mãe, sem 
rebelar-se contra as arbitrariedades mesquinhas da inveja materna. O próprio comportamento de Erika, em muito, se assemelha ao da mãe, neste caso, no entanto, não é a inveja que a motiva a ficar, mas sim o conforto. Esse conforto não se restringe somente ao sentido material, ele envolve igualmente os aspectos anímicos, já que ela entrevê na mãe sentimentos semelhantes aos que ela mesma experimenta. Ao vislumbrar uma companheira de martírio, a inaceitabilidade de suas emoções é mitigada. Assim acaba assentindo em que a mãe interfira em seus relacionamentos sociais, para suportar seus próprios sentimentos, mas também para, dessa maneira, esquivar-se da responsabilidade de criar independentemente seus próprios laços sociais. Aceitando a inveja materna e anuindo à sua intromissão ininterrupta, Erika possui os elementos necessários para narrar uma história diante do foro interior que a libera da responsabilidade, em princípio, intransferível da organização da própria existência. A mãe, com seus ímpetos de inveja, serve de instrumento de legitimação pessoal para o fracasso da filha. Erika, portanto, não se submete aos caprichos da mãe, ela os instrumentaliza.

Essa dinâmica de interação, patenteando os meandros entre motivação, ação e narração, emerge também da inveja que a mãe alimenta pelas roupas da filha. Semelhante 
à restrição do círculo social incutido pela mãe, também as vestimentas usadas por Erika passam pelo controle materno, antes que a filha possa exibi-las publicamente. Embora ciente dessa arbitrariedade, Erika prefere assentir, mas não sem obrar comedidos atos de revolta:

A mãe nem sempre consegue evitar que a filha os compre, mas é ela quem determina se eles vão ou não ser usados. E não existe nada que possa restringi-la nesse setor. É a mãe quem determina de que jeito Erika vai sair de casa. Assim é que você não vai sair, determina a mãe, que tem medo de que a filha entre em casas estranhas com homens estranhos vestida daquele jeito. (JELINEK, 2011, p.16)

Toda essa encenação contém uma narração inarticulada cuja superfície tem a finalidade de legitimar uma emoção banida. Ao proibir peremptoriamente que sua filha saia vestida com os trajes adquiridos por ela mesma, a mãe emprega o modelo narrativo da genitora, preocupada com a imagem social a ser produzida por meio de signos indumentários que, de seu ponto de vista, são inadequados. Interiormente, temendo que sua filha venha a encontrar homens cuja conduta imprevisível possa pô-la em perigo, a mãe encontra o motivo que lhe proporciona o fundo ético necessário para legitimar sua aversão aos vestidos e ao ímpeto de exibi-los. A fala da mãe, em discurso indireto 
livre, substitui abruptamente no trecho citado acima a voz do narrador, em uma ordem negativa, que a um só tempo revela o prevalecimento da mãe sobre Erika e a anulação da filha, pela formulação negadora da possibilidade de ação.

Em nenhum momento, a verdadeira motivação penetra a consciência materna ou se descobre de alguma maneira incluída no nexo causal. Muito pelo contrário, toda a argumentação que envolve os atos maternos representa estratégias de legitimação, fazendo uso sempre daqueles aspectos que melhor se incorporam à narração social ou interior. Essa estratégia representa, por um lado, um instrumento social de manipulação que facilita a indução planejada dos atos da filha. Por outro lado, iguala-se a um aparato de autoproteção que permite à mãe sublimar seus sentimentos, sem que esta se veja forçada a repensar sua verdadeira motivação. Assim sua dignidade e narração permanecem inabaláveis, sem ter de admitir que aquilo que a impele é a inveja da beleza da filha, possivelmente potenciada pela vestimenta, ou da possibilidade desta de encontrar um parceiro que lhe proporcione prazer ou que possa presenteála com sentimentos como amor e carinho, tecendo uma rede teleológica que, por sua vez, torna a presença materna obsoleta e indesejada: "Para a mãe, esses vestidos são sinais de egoísmo. Mas o egoísmo da filha fica evidente, também, 
porque já passa das onze e a mãe continua sozinha consigo mesma. Ela não pode se sujeitar a semelhante atrevimento" (JELINEK, 2011, p.172). Diante desse perigo, a única estratégia que resta à mãe é uma interpretação da realidade que the seja favorável, explicitada como tal no texto ("Para a mãe,") e funcionalizada como marcador de prosseguimento da trama ("mãe continua sozinha", logo "não pode se sujeitar a semelhante atrevimento").

\section{RELAÇÕES ENTRE PROFESSORA E ALUNOS}

A irradiação da inveja não perpassa somente o círculo primordial da família, ela se propaga igualmente a outros paradigmas de interação social como a relação professoraluno. Impedida de exercer a profissão de musicista num âmbito glorioso ou, de alguma maneira, condizente com sua autoimagem, Erika se vê obrigada a diminuir-se para garantir sua sobrevivência. Embora saiba que sua situação se deve primariamente a suas limitações de talento, ela escolhe não articulá-lo dessa maneira, preferindo dar outro foco a sua atenção. Instigada pela mãe, já não enxerga seus alunos como companheiros, mas antes como inimigos que possivelmente venham a angariar um êxito que ela mesma jamais obteve:

Porém você permite que eles apareçam! E na verdade poderia muito bem refreálos! Mas para isso você é incompetente 
demais, Erika. Quando a professora evita, de forma decidida, nenhuma aluna mais jovem se destaca, pelo menos não na sua classe, nem faz carreiras indesejáveis e imprevistas como pianista. Você mesma não conseguiu. Então, por que agora outras deveriam conseguir no seu lugar, e ainda mais saídas do seu curralzinho pianístico? (JELINEK, 2011, p.16)

A mãe não hesita em incitar a filha a alimentar sentimentos mesquinhos. De sua perspectiva materna, o que não dá direito às outras alunas de alcançarem o sucesso que sua própria filha não obteve está vinculado a seu conceito de justiça. Ao crer que sua filha foi injustiçada pela vida, pela sociedade e pelos meios artísticos, e em nome dela também a mãe que não logra desvincular-se do bloco narrativo "filha", se arroga o direito de bradar a suposta sensação de retidão ferida sem quaisquer contenções éticas. A sensação de injustiça, por sua vez, legitima a incitação à vileza e torna a inveja mascarada em um sentimento superficialmente lícito. Portanto, essa partícula de interação social, em cujo centro borbulha o pus da inveja, apresenta novamente um princípio de construção e figuração baseado numa discrepância insuperável entre motivação e narração pessoal e social. A repressão do sentimento vil, ou melhor, sua sublimação por meio de elementos argumentativos estabelecidos e socialmente 
acatados se transforma num elemento que caracteriza a força motriz de uma série de interações e portanto um elemento decisivo para a constituição do enredo e da trama do romance.

Impelida pela sensação de injustiça e sem consciência da verdadeira motivação, Erika transporta esse modelo de interação para além das fronteiras estabelecidas pela sala de aula, procurando seus alunos em outros contextos, para assim controlá-los melhor. Embora essa procura seja incitada pela necessidade de interagir, ela não tem o objetivo de tecer laços pessoais com o fim de construir uma rede social que a beneficie de alguma maneira em outras situações de sua vida pessoal. Muito pelo contrário, em nenhum momento, esquece sua posição hierarquicamente superior, pois é justamente essa postura que legitima sua intromissão arbitrária.

Talvez hoje ela apanhe um aluno ou aluna que, desconhecendo o que significa a carga de estudos de um músico, ainda tenha tempo livre em demasia e se ocupe com sua vida própria e particular? Erika quer penetrar à força nesses campos vastos que se alastram, divididos em lotes, e que ainda assim fogem a seu controle. Morros sangrentos, campos de vida, nos quais o que vale é ocultar os próprios desejos. O professor tem todo o direito de agir dessa forma, pois ele é um 
representante dos pais. Ela quer saber, a qualquer custo, o que se passa em outras vidas. (JELINEK, 2011, p.114)

O ímpeto da personagem principal de buscar informações sobre a vida de seus alunos não está vinculado, como já foi mencionado, a um interesse social, pois o que ela certamente não procura são amigos ou informações para praticar alguma ação filantrópica. Sua motivação para a busca de uma interação tem outra origem, a saber, a suposição de que seus alunos tenham tempo suficiente para construir uma vida pessoal com laços sociais que lhes assegurem prazer existencial, além do árduo treino musical. Trata-se de uma experiência que Erika jamais vivenciou, porque se dedicou exclusivamente ao alcance da excelência musical, abdicando assim dos prazeres da vida íntima. O que a move é a necessidade patológica de verificar a certeza de suas conjecturas envidiosas, para assim legitimar as acusações de falta de assiduidade dos alunos e sentir-se superior.

Essa passagem revela outros aspectos igualmente importantes para patentear a motivação inerente à interação da protagonista. A riqueza linguística de Jelinek se evidencia nas metáforas empregadas para descrever o relacionamento com os alunos de música. Estas estão saturadas de erotismo. A necessidade de "penetrar", "introduzir-se" ou "aferrar-se" 
evidencia indiretamente um ímpeto erótico obviamente não satisfeito. O olhar invejoso, por conseguinte, está vinculado a um bem não alcançado por Erika, mas usufruído sem grande esforço, ao menos em sua imaginação, por seus alunos, que para isso se esquivam de seus deveres musicais. Logo, suas interações, legitimadas pelo papel da mestra exigente e preocupada, se reduzem a uma motivação cujo teor se resume a uma tentativa de conviver com a amargura da necessidade irresoluta.

Para isso, ela se dá o direito de arbitrar sobre a vida alheia e, sem quaisquer melindres, de adentrar os espaços restritos da intimidade de seus alunos, legitimando essa interação desrespeitosa com a abdicação paterna da guarda dos filhos. A despeito de sua falta de reflexão sobre suas sucessivas transgressões espaciais e comunicativas, a visão figural de Erika, no entanto, indica um desconforto liminar, não articulado em relação à sua atitude arbitrária. O fato de legitimar constantemente seus atos envidiosos com um discurso arraigado numa ética burguesa e em valores tradicionais mostra que, ao menos, ela intui a impropriedade de seus modelos de interação. Isso, no entanto, não a impede de desenfrear sua curiosidade, para assim arraigar-se ainda mais profundamente na intimidade de seus alunos, mantendo o círculo vicioso da inveja em movimento constante. 
As informações recolhidas nessas saídas de reconhecimento servem, mais tarde, de base para outras interações com a mãe. O sentimento de inveja, justificado e conscientemente admissível pela sensação de injustiça, representa o fundamento para acusar a mãe de mantêla arbitrariamente em casa, impedindo assim que a filha tenha qualquer chance de tecer uma rede de novos contatos ou de inovar sua aparência para de tal modo aumentar a probabilidade de vivenciar algo que exceda à sua rotina. Ao culpar a mãe, ela automaticamente se esquiva da responsabilidade pelas próprias interações, além de reprimir sagazmente a verdadeira motivação que a leva às acusações. O fato de grande parte do material comunicativo existente nessas conversas estar vinculado a conteúdos que remontam por intricados caminhos argumentativos ao sentimento primordial da inveja, o motor factual da comunicação, revela uma profunda necessidade experimentada por parte da protagonista de dar conta desse excesso emotivo impassível de ser integrado harmoniosamente em sua narração pessoal. Ao abordar esse tema, empregando acusações ou argumentos cujo fim é mostrar a injustiça vivenciada, ela transforma seu sentimento vil em algo, ao menos parcialmente, apresentável. 


\section{DIÁLOGOS ENTRE GERAÇÕES}

A interação entre professora e alunos ou entre mãe e filha se torna ainda mais complexa, ao envolver as pulsações de inveja que latejam entre as gerações. Toda geração é movida por desejos e objetivos próprios, reverberando nos filhos ou nos alunos as experiências que marcaram a existência. Comedida, essa reverberação sublinha os elementos biográficos da pessoa em ação. Ela pode, no entanto, materializar-se também em forma de dois extremos: por um lado, a exigência implacável de alcançar aquilo que os pais ou professores mesmos não atingiram, por outro lado, o receio de que a próxima geração seja justamente capaz de fazer tudo aquilo que a anterior omitiu, provando dessa maneira a inferioridade daqueles que sempre afirmaram sua superioridade intelectual. Muitas interações acabam sendo pautadas por esses dois elementos, exigência e receio.

Em diversos aspectos, esses dois pilares caracterizam o espaço no qual Erika é impelida a agir. A mãe expressa continuamente seu desejo de que sua filha se torne uma musicista internacionalmente reconhecida, ao mesmo tempo, teme, com um desespero existencial, que ela venha a obter uma autonomia que a torne, como mãe, dispensável. Mãe e avó, por conseguinte, se dedicam a guiá-la nesse 
caminho, em detrimento de quaisquer impulsos pessoais e independentes que Erika ouse expressar:

As duas mulheres mais velhas, com seus órgãos sexuais ressecados, se atiram sobre todos os homens, para que eles não se aproximem de sua cabritinha. $O$ amor e o desejo não devem prejudicar de maneira nenhuma o animalzinho. (JELINEK, 2011, p.43)

A inveja do suposto prazer sexual, a intuição da possibilidade remota de construção independente de uma vida íntima ou o pressentimento da incipiente seção dos laços filiais impedem a geração anterior de aceitar a visão de um caminho alternativo que não esteja em consonância com os meandros percorridos e estabelecidos no passado. Obviamente, esse comportamento mesquinho tem de ser legitimado de alguma maneira, o que se dá através da narração da superioridade de experiência e da necessidade de proteção da prole. Essa moral dupla acaba sendo desmascarada como algo dúbio e vil, transformando a imagem do amor altruísta, num resquício da ideia primordial.

Essa passagem, com sua animalizacão do humano, como também os excertos subsequentes em que se dá a deformação da pessoa 'Erika' num pedaço de carne suscita imagens do grotesco. Cramer ${ }^{1}$ define o grotesco da seguinte 
forma: "grotesco é a sensação de medo desencadeada pelo cômico exagerado; essa equação, como ainda tem de ser mostrado, também pode ser invertida: o grotesco é um medo do inexplicável combatido pelo cômico"2 (1970, p.26). Essa categoria estética é empregada repetidamente por Jelinek para criar uma rede de comicidade, mas também para mostrar a insegurança das personagens. O medo encoberto por trás da imagem cômica remete a um perigo existencial vislumbrado pelas duas velhas senhoras.

Torturadas pela inveja e oprimidas pela necessidade de uma narração socialmente aceitável, mãe e avó se torcem para moldar Erika a sua imagem. Esta, incapaz de articular suas necessidades ou de escapar aos mecanismos de controle impostos pela mãe, consente, mas não sem perceber que suas chances se esvaem e que seus desejos permanecem insatisfeitos, reconstruindo assim o círculo vicioso da inveja: "Elas cortam a vida DELA em grossas fatias, e as vizinhas já pensam em Ihe arranjar um casamento. E cada fatia onde ainda se encontra um pouco de vida é considerada podre e arrancada" (JELINEK, 2011, p.44). As "grossas fatias" podem simbolizar um mundo capitalista em que o outro se tornou um objeto, mas podem indicar também uma opção estética para indicar o medo do absurdo e do

2 "grotesk ist das durch übersteigerte Komik ausgelöste Gefühl der Angst, wobei sich diese Gleichung, wie noch zu zeigen ist, umkehren läßt: grotesk ist die durch Komik bekämpfte Angst vor dem Unerklärbaren" (CRAMER, 1970, p.26). 
inexplicável que Ihes escapa. Incapacitada de expressar seus anseios e sem espaço para seguir os impulsos de seu corpo, Erika se vê condenada ao caminho da inveja, retomando, portanto, o mesmo rumo da geração anterior.

A redução drástica de espaço vital obviamente influi decisivamente em seus modelos de interação. Impedida de desbravar novas coordenadas sociais em que pudesse dar rédeas soltas a suas necessidades ou livrar-se da pressão de condizer à imagem imposta pela geração anterior, Erika experimenta a sensação de sufoco, pois se vê obrigada a remodelar todo e qualquer movimento de acordo com expectativas alheias, para não sofrer repressões que implodiriam seu espaço privado. Encurralada, ela experimenta uma profunda sensação de impotência e de incapacidade para frear as arbitrariedades maternas ou impor suas próprias fronteiras. O que lhe resta é olhar de soslaio as oportunidades na vida dos outros:

Hoje Erika tem o dobro da idade de uma menina de dezoito anos! Ela repete a conta, incessantemente, e a distância entre Erika e uma menina de dezoito anos nunca diminui, mas também não aumenta. A antipatia que ela sente por todas as meninas dessa idade ainda aumenta desnecessariamente essa distância. Suando, Erika gira, durante as suas noites, no espeto do ódio, sobre 
o fogo ardente do amor materno. E, enquanto gira, é regada, a intervalos regulares, com o molho perfumado do assado da arte musical. Não há nada que seja capaz de mudar essa diferença inexorável: velho/jovem. (JELINEK, 2011, p. 214)

A imagem do "espeto do ódio" - indicando como a linguagem literária de forte apelo imagético reflete e explicita as emoções - enfatiza o sufoco experimentado, ao mesmo tempo, sublinha a inexistência quase completa de um espaço passível de ser transformado num lugar em que possa, de fato, medrar. O amor materno flagela Erika, enquanto a música Ihe proporciona, no máximo, um alívio passageiro, sem ser capaz de libertá-la dos martírios aos quais se vê condenada. Acuada, já não consegue desfazer-se de sentimentos vis, invejando e odiando desesperadamente qualquer mulher que ainda tem a chance de realizar seus desejos pessoais e impor seu próprio cunho ao espaço que a circunda. O "espeto do ódio", as "grossas fatias" ou a carne "podre" retomam o grotesco, introduzindo imagens coisificadas, horripilantes e nauseabundas do ser humano. O irracional desconhecido e não compreendido se concretiza em forma do cômico.

Esse processo, contudo, já tem início muito cedo na infância de Erika. Agrilhoada às imposições patológicas de sua mãe, Erika tem de aprender rapidamente como interagir no roteiro 
escrito por ela. Com isso, surge a necessidade de um constante jogo duplo que lhe permita conviver com as regras maternas e encontrar pequenas lacunas para atender necessidades não sancionadas. Simulando uma ingenuidade infantil sacrificada há muito tempo, a musicista encena diante dos outros a personagem implicitamente desejada pela mãe, renunciando assim a um desenvolvimento natural, ou seja, em consonância com suas próprias vontades. O olhar ou o ouvido envidioso recai, por conseguinte, sempre no mundo inalcançável:

Com um ouvido ELA presta atenção ao barulho que seu primo está fazendo com as meninas lá fora. Ouve como ele enfia dentes sadios no tempo e o devora, com apetite. A cada segundo, ELA tem uma consciência dolorosa do tempo, e seus dedos marcam os segundos nas teclas, como se fossem a máquina de um relógio. (JELINEK, 2011, p.50)

Desejosa, mas incapaz de aproximar-se, ela prefere observar de longe, pois a inserção nesse grupo lhe patentearia sua alteridade e a forçaria a repensar sua narração pessoal. Esse processo sendo muito doloroso, ela se esquiva da interação com um olhar distante, mas invejoso.

A consequência desse isolamento absoluto é a crença cada vez mais irrevogável de sua autossuficiência, ao mesmo tempo, um afastamento gradual de barreiras éticas 
imprescindíveis para a convivência social. Em nenhum momento, ela mostra ter consciência de que se encontra num círculo vicioso do qual não consegue libertar-se. Embora se aperceba de seu isolamento e da indiferença mostrada por outros para com ela, Erika não consegue mudar seus modelos de interação, acabando por desenvolver desejos patológicos para dar conta das turbulências desencadeadas pelo isolamento.

Com o passar dos anos os SEUS desejos inocentes se transformam numa cobiça destrutiva, em vontade de destruir. Tudo o que os outros têm, ela também quer ter, à força. E tudo o que ela não pode ter, quer destruir. Ela começa a roubar as coisas. No ateliê no sótão, onde são realizadas as aulas de pintura, desaparecem exércitos inteiros de aquarelas, lápis, pincéis, réguas. (JELINEK, 2011, p.97) O acúmulo de frustração, a inexistência de alternativas e, sobretudo, o efeito corrosivo da inveja a impelem a apoderar-se dos objetos cobiçados, sem mesmo ter o objetivo de permanecer com eles. O desejo de destruição que a consome e, com isso também, toda a hostilidade gerada em decorrência das diversas tentativas frustradas concorrem numa enorme sensação de sufoco, angústia e desespero, impassível de ser amenizada nem mesmo pelos efeitos sublimatórios da arte. 
Fundadas na inveja, todas tentativas de interação fracassam pela falta completa de empatia, magnanimidade e um mínimo de satisfação com o destino a ela outorgado. O que surge é uma paisagem patológica (SWALES, 2000) cada vez mais concreta.

Esse desespero alcança uma acuidade insuportável quando Erika vislumbra no interesse de seu aluno Walter Klemmer a possibilidade de encontrar uma satisfação que ela intui distantemente. Ao perceber que outra mulher sequestra a atenção dele com ajuda de seus predicados eróticos e seu status social, prenunciando, portanto, um perigo iminente, Erika não hesita em fazer uso de métodos que neutralizem sua rival o mais rapidamente possível. Decidida a desfazer-se do perigo sem grandes cerimônias, coloca cacos de vidro no sobretudo de sua inimiga, para que esta, com as mãos cortadas, tenha de sair do âmbito de visão de Klemmer.

\section{CONSIDERAÇÕES FINAIS}

Esses últimos episódios mostram que os modelos de interação ocasionados pelo sentimento de inveja transgridem uma série de convenções sociais, sem as quais o convívio em sociedade se tornaria impossível. Erika obviamente é o resultado de diversas coerções, por parte da mãe, dos 
colegas de aula, de companheiros de trabalho, de alunos, de pessoas que a rodeiam. A consequência dessas coações é seu isolamento absoluto, levado ao extremo pela necessidade concomitante de um sentimento de superioridade como meio de autoproteção. Seu ímpeto irrefreável de provar-se superior aos outros está vinculado ao medo de ser desmascarada como alguém que não está à altura de ocupar a posição social defendida. Seu isolamento poderia significar um afastamento dos modelos sociais instituídos e acatados pela maioria, Erika, porém, os almeja, querendo fazer parte deles.

Embora a caracterização e toda a construção estética da figura "Erika" raramente evoque no leitor a impressão de que seja uma vítima, sua inveja doentia e, concatenada a ela, suas interações grotescamente hostis acabam revelando sua tragicidade. Presa de seu próprio destino e, sobretudo, de suas emoções agressivas, Erika não logra criar um ambiente vital em que possa desenvolver-se de acordo com suas próprias necessidades. Incapaz de comunicarse com signos desprovidos de inveja, ela sufoca todas suas interações na raiz e recorre à agressão para dar conta das frustrações. A professora de música, embora cercada pelos signos libertadores da arte, é uma marionete de suas próprias emoções, destruindo tudo aquilo que the poderia proporcionar prazer. 


\section{REFERÊNCIAS}

BURGER, Rudolf (1990). Der böse Blick der Elfriede Jelinek. In: GÜRTLER, Christa (Org.). Gegen den schönen Schein: Texte zu Elfriede Jelinek. Frankfurt am Main: Neue Kritik. p.17-29.

CRAMER, Thomas (1970). Das Groteske bei E. T. A. Hoffmann. München: Wilhelm Fink.

JELINEK, Elfriede (2004). Die Klavierspielerin. Hamburg bei Reinbek: Rowohlt.

. (2011). A Pianista. Luis S. Krausz (Trad.). São Paulo: Tordesilhas.

SCHOECK, Helmut (1987). Envy. A theory of social behaviour. Michael Glermy; Betty Ross (Trad.). Indianapolis: Liberty Press.

SCHOLZ, Anna-Lena (2010). Sprechende Blicke: Entwürfe zu einer Poetik und Grammatik des Blicks (Elfriede Jelinek: 'Die Klavierspielerin'). In: CALHOON, Kenneth S.; GEULEN, Eva; HAAS, Claude; RESCHKE, Nils (Orgs.). 'Es trübt mein Auge sich in Glück und Licht': Über den Blick in der Literatur. Berlin: Schmidt. p.242-256.

SWALES, Erika (2000). "Pathography as Metaphor: Elfriede Jelinek's Die Klavierspielerin”. Modern Language Review, 95 (2), p.437-449.

WILKE, Sabine (1993). "'Ich bin eine Frau mit einer männlichen Anmaßung': Eine Analyse des 'bösen Blicks' in Elfriede Jelineks Die Klavierspielerin". Modern Austrian Literature, 26 (1), p.115-144.

Dionei Mathias - Professor Adjunto do Departamento de Letras Estrangeiras Modernas, na Universidade Federal de Santa Maria. Doutor em Letras pela Universidade de Hamburgo (2011) e pela Universidade Federal do Paraná (2014). Contato: dioneimathias@gmail.com 